\title{
Commentary
}

\author{
HORMONE \\ RESEARCH IN \\ PAEDIATRICS
}

Horm Res Paediatr 2016;86:357-360

DOI: $10.1159 / 000449275$
Received: August 11, 2016

Accepted: August 12, 2016

Published online: September 30, 2016

\section{Small at Birth, but How Small? The Definition of SGA Revisited}

\author{
Daniel Zeve ${ }^{a}$ Molly O. Regelmann ${ }^{b}$ lan R. Holzmanc Robert Rapaport ${ }^{b}$ \\ ${ }^{a}$ Department of Pediatrics, Icahn School of Medicine at Mount Sinai, and Divisions of bediatric Endocrinology and \\ Diabetes and ' Newborn Medicine, Department of Pediatrics, Icahn School of Medicine at Mount Sinai, New York, \\ N.Y., USA
}

Being born small has been associated with many shortand long-term health sequelae. Perinatally, it is associated with increased mortality, lung disease, hypotension, necrotizing enterocolitis, poor thermoregulation, hypoglycemia, and polycythemia $[1,2]$. Long-term, small infants are at risk for insulin resistance, type II diabetes mellitus, cardiovascular disease, chronic kidney disease, neurodevelopmental and cognitive impairments, developmental delays, behavioral problems, and adult short stature [1].

But how 'small' is 'too small'? The term 'small for gestational age' (SGA) describes newborns who have lowerthan-expected weight, length, and/or head circumference when controlled for gestational age and sex. This is different from intrauterine growth retardation, which refers to poor growth in utero evidenced by at least two ultrasound measurements [2], and prematurity, which is a broad term defining neonates born prior to 37 weeks gestation. Some, but not all, infants with intrauterine growth retardation and/or prematurity may be born SGA.

In spite of potential significant health implications, the exact definition of SGA remains elusive. Multiple criteria have been used, including less than the 10th, 5th, and 3rd percentile in weight, length, or head circumference. Another definition of SGA is parameters more than 2 standard deviations (SDs) below the mean, or the 2.3rd percentile $[1,2]$. These discrepancies are not novel, with over
50 years of published discussion of the definition of SGA [3-5]. The 10th percentile was chosen as a cutoff for SGA in the 1960 s as a result of multiple studies indicating that infants born at or below the 10th percentile have increased mortality compared to gestational age-matched controls [4]. It is worth noting that these studies were performed on neonates born at high altitudes, who tend to be smaller compared to those born at sea level $[4,5]$. Defining SGA as 2 SDs below the mean was also suggested in the 1960s, as it would only define $4.6 \%$ of births as abnormal (approximately 2.3\% SGA and $2.3 \%$ large for gestational age), as opposed to 20\% (10\% SGA and 10\% large for gestational age). Additionally, the 2 SD cutoff roughly corresponded with an earlier study reporting that $2.3 \%$ of neonates were born at $25 \%$ below the mean weight when controlled for gestational age [5].

In 1995, the World Health Organization published recommendations defining SGA as less than the 10th percentile of weight for gestational age using localized anthropometric newborn curves [3]. In 2007, a consensus meeting that included representatives from seven international pediatric endocrinology societies, as well as a representation from obstetrics, perinatology and neonatology, pediatrics, epidemiology, and pharmacology, recommended that SGA be defined as more than 2 SDs below the mean for weight and/or length [2]. They also rec-

\section{KARGER}

(c) 2016 S. Karger AG, Basel

E-Mail karger@karger.com

www.karger.com/hrp
Robert Rapaport, MD

Division of Pediatric Endocrinology and Diabetes

Icahn School of Medicine at Mount Sinai

1 Gustave L Levy Place, Box 1616, New York, NY 10029 (USA)

E-Mail robert.rapaport@mountsinai.org 
Table 1. Definitions of SGA used in publications from 2010 to 2015

\begin{tabular}{lllll}
\hline & $<10$ th percentile & $<2$ SDs & Other & Not defined \\
\hline Journal of Pediatrics & $29(72.5)$ & $3(7.5)$ & $3(7.5)$ & $5(12.5)$ \\
Pediatrics & $17(53.1)$ & $6(18.8)$ & $4(12.5)$ & $5(15.6)$ \\
Journal of Perinatology & $18(69.2)$ & $0(0.0)$ & $2(7.7)$ & $6(23.1)$ \\
JCEM & $15(35.7)$ & $17(40.5)$ & $2(4.8)$ & $8(19.0)$ \\
\hline
\end{tabular}

Data are given as n (\% of total). JCEM = Journal of Clinical Endocrinology and Metabolism. Articles using the term 'small for gestational age' (SGA) from 2010 to 2015 were identified in the journals listed. Not defined: the definition for SGA was not clearly stated in the published article, but the term 'SGA' was used. Other definitions: $<5$ th percentile, $<3$ rd percentile, $<2.5$ th percentile, $<1 \mathrm{SD},<2,500 \mathrm{~g}$.

Table 2. Studies comparing different definitions of SGA

\begin{tabular}{|c|c|c|c|}
\hline & $\begin{array}{l}>2 \text { SDs or } \\
<3 \text { rd percentile }\end{array}$ & $\begin{array}{l}<10 \text { th } \\
\text { percentile }\end{array}$ & Ref. \\
\hline Risk ratio of neonatal death (SGA compared to births at the $25-75$ th percentile) at term & 6.28 & 3.51 & 6 \\
\hline Mortality from 1 to 14 years in those born SGA, per 1,000 & 20.2 & $5.5^{1}$ & 7 \\
\hline $\begin{array}{l}\text { Increased long-term maternal risk of developing cardiovascular disease after SGA } \\
\text { delivery compared to AGA }\end{array}$ & $66 \%$ & $36 \%^{2}$ & 9 \\
\hline
\end{tabular}

The referenced articles included in this table describe studies looking at health outcomes in those born SGA. In these studies, SGA was defined in multiple ways, including $>2$ SDs below the mean, $<3$ rd percentile, and $<10$ th percentile. ${ }^{1}$ Did not include those born SGA for weight at $<2$ SDs below the mean. ${ }^{2}$ Did not include those born SGA for weight $<3$ rd percentile.

ommended the use of a subscript to identify the anthropometric measure used (weight, length, head circumference) to define SGA. The more than 2 SD definition was chosen, in part, because it identified 'the majority of those in whom ongoing growth assessment is required' [2].

However, 9 years after the publication of the above consensus, it appears that this information did not receive adequate dissemination or acceptance. Over the last 5 years, researchers and clinicians have continued to use different parameters to define SGA (table 1), with articles published in leading endocrinology journals using more than 2 SDs as the cutoff for SGA much more often than articles published in journals which focused on general pediatrics and neonatology.

Due to this lack of a unified definition, studies may arrive at different conclusions when examining the health implications of being born SGA. This is shown in studies that examine health outcomes using multiple definitions of SGA (table 2). For instance, the relative risk ratios of neonatal death and a 5-min Apgar score of less than 4 for those born SGA compared to those born appropriate for gestational age (AGA) are much higher when SGA is defined as less than the 3 rd percentile versus the 10th percentile [6]. Long-term mortality risk of those born SGA $[7,8]$ and long-term maternal risk of cardiovascular disease when giving birth to SGA infants [9] also vary depending on the SGA definition (table 2).

In two separate studies, the occurrence of metabolic syndrome was examined in obese children born either AGA or SGA for weight, with each study utilizing a different definition for SGA. When SGA was defined as less than the 10 th percentile, $40 \%$ of obese children born SGA had metabolic syndrome compared to $17 \%$ of those born AGA; when SGA was defined as greater than 2 SDs below the mean, only $11 \%$ of obese children born SGA had metabolic syndrome compared to $9 \%$ of those born AGA [10, 11] (table 2). This difference could be attributable to mul- 
tiple factors, including different study populations, statistical analyses, as well as the inclusion/exclusion of those born between the 2.3 and 10th percentile.

Catch-up growth in term patients born SGA, defined as greater than 2 SDs below the mean, has been generally expected to occur in $>86 \%$ of subjects by 1 year of age [12]. In a recent study defining SGA as less than the 5th percentile at 9 months of age, $79 \%$ of patients were felt to have caught up [13]. It is not known how long-term growth data may differ if the definition of SGA were less than the 10th percentile. For children who do not have adequate catch-up growth, the definition of SGA affects future management. Currently, children born SGA, defined as greater than 2 SDs below the mean, and who have not adequately caught up by 2 years of age, are eligible for treatment with recombinant human growth hormone as per the Federal Drug Administration guidelines [2]. Children diagnosed as SGA based on definitions of less than the 5 th or 10th percentile but above 2 SDs are not eligible for treatment based on birth parameters.

We are aware of very few studies that analyze shortand long-term data in infants born small, using a continuum of SGA definitions. Aside from those already noted in table 2 , another study showed no difference in the incidence of hypoglycemia in term infants born SGA when comparing birthweight below the 5th percentile to birthweight between the 5th and 10th percentile [14]. Additionally, a study examining the incidence of neonatal enterocolitis in those born SGA showed a higher percentage of neonatal enterocolitis in those born with a birthweight less than the 2.3rd percentile and between the 2.3rd and 5 th percentile when compared to those born between the 5 th and 10th percentile, although this was not statistically significant [15]. Other research concerning health consequences of being born SGA, including primary hypertension risk [16], adult hormonal response to psychosocial stress [17], long-term maternal cardiovascular morbidity [18], and risk of long-term maternal renal disease [19] define SGA as below the 10th percentile, preventing stratification of risk based on differing percentiles and possibly including patients who may not, in fact, be at risk.

On the other hand, studies concerning the cardiovascular risk profile [20], cardiac morphometry, cardiac function, and arterial biophysical profile at $2-5$ postnatal days [21], and short stature [1,22] define SGA as either below the 3 rd percentile or greater than 2 SDs below the mean, excluding all other percentiles below the 10th percentile and possibly patients who may be at risk.

As advances in neonatal care result in more infants born premature or small surviving, more patients require long-

Definition of Small for Gestational Age term monitoring for the potential risks associated with being born small. It is therefore imperative that a consensus involving all stakeholders, as convened previously in 2007 [2], be reached for the definition of SGA, in order to develop evidence-based practice guidelines for the prevention and management of the health consequences of low birth size. Research should define the population in a uniform way so the results and outcomes of both retrospective analyses of existing databases and prospective studies can be correctly analyzed, thus providing long-term properly documented data to inform current clinical practice.

We strongly recommend studies involving those born SGA to compare what, if any, differences are noted when multiple definitions of SGA are used. For example, stratifying results based on different percentile ranges, including less than the 2.3rd percentile, the 2.3 rd to 5 th percentile, and the 5th to 10th percentile allows for broad patient inclusion with the ability to further define the most atrisk population of patients born SGA.

The new consensus should also include recommendations regarding the most suitable anthropometric curves to use at birth, including the possible use of the recently published international newborn standards $[23,24]$, and outline a uniform way to obtain measurements, especially for infant length. It is also important that an etiology-based separation of infants born SGA be developed, as the risk of complications may vary secondary to the cause of SGA. For example, a patient born SGA secondary to Silver-Russell syndrome may not show the same health profile as an infant born SGA secondary to placental insufficiency or maternal alcohol exposure $[1,2]$. Early identification of the etiology will allow for the most appropriate interventions to be selected. Part of the consensus conference should also be the identification of effective methods for the dissemination of the adopted recommendations, such as print and web-based circulation in recognized forums.

In conclusion, to unify research, and thus guide evidence-based medicine and healthcare policy, a new consensus regarding size at birth, its definition, causes, and consequences is needed. Participants should include all who take care of these infants from preconception through adult life. Guidelines should be developed to identify etiology, anthropometrics, definitions, and outcome analyses for all infants born small.

\section{Disclosure Statement}

The authors have no conflicts of interest and no financial relationships relevant to this article to disclose. 


\section{References}

$>1$ Saenger P, Czernichow P, Hughes I, Reiter EO: Small for gestational age: short stature and beyond. Endocr Rev 2007;28:219-251.

$\checkmark 2$ Clayton PE, Cianfarani S, Czernichow P, Johannsson G, Rapaport R, Rogol A: Management of the child born small for gestational age through to adulthood: a consensus statement of the International Societies of Pediatric Endocrinology and the Growth Hormone Research Society. J Clin Endocrinol Metab 2007;92:804-810.

3 WHO Expert Committee: Physical Status: The Use and Interpretation of Anthropometry: Report of a WHO Expert Committee. Geneva, World Health Organization, 1995.

4 Battaglia FC, Lubchenco LO: A practical classification of newborn infants by weight and gestational age. J Pediatr 1967;71:159-163.

$\checkmark 5$ Usher R, McLean F: Intrauterine growth of live-born Caucasian infants at sea level: standards obtained from measurements in 7 dimensions of infants born between 25 and 44 weeks of gestation. J Pediatr 1969;74:901-910.

-6 Xu H, Simonet F, Luo ZC: Optimal birth weight percentile cut-offs in defining smallor large-for-gestational-age. Acta Paediatr 2010;99:550-555

7 Rantakallio P: A 14-year follow-up of children with normal and abnormal birth weight for their gestational age. A population study. Acta Paediatr Scand 1985;74:62-69.

$\checkmark 8$ Wennerstrom EC, Simonsen J, Melbye M: Long-term survival of individuals born small and large for gestational age. PLoS One 2015; 10:e0138594.

$\checkmark 9$ Ngo AD, Roberts CL, Chen JS, Figtree G: Delivery of a small-for-gestational-age infant and risk of maternal cardiovascular disease a population-based record linkage study. Heart Lung Circ 2015;24:696-704.

10 Reinehr T, Kleber M, Toschke AM: Small for gestational age status is associated with metabolic syndrome in overweight children. Eur J Endocrinol 2009;160:579-584
11 Stroescu R, Micle I, Bizerea T, Puiu M, Marginean $\mathrm{O}$, Doros G: Metabolic monitoring of obese children born small for gestational age. Obes Res Clin Pract 2014;8:e592-e598.

12 Karlberg J, Albertsson-Wikland K: Growth in full-term small-for-gestational-age infants: from birth to final height. Pediatr Res 1995; 38:733-739.

13 Maciejewski E, Hamon I, Fresson J, Hascoet JM: Growth and neurodevelopment outcome in symmetric versus asymmetric small for gestational age term infants. J Perinatol 2016; 36:670-675.

14 Mejri A, Dorval VG, Nuyt AM, Carceller A: Hypoglycemia in term newborns with a birth weight below the 10th percentile. Paediatr Child Health 2010;15:271-275.

15 Ree IM, Smits-Wintjens VE, Rijntjes-Jacobs EG, Pelsma IC, Steggerda SJ, Walther FJ, Lopriore E: Necrotizing enterocolitis in small-for-gestational-age neonates: a matched case-control study. Neonatology 2014;105:74-78.

16 Pocobelli G, Dublin S, Enquobahrie DA, Mueller BA: Birth weight and birth weight for gestational age in relation to risk of hospitalization with primary hypertension in children and young adults. Matern Child Health J 2016;20:1415-1423.

17 Kajantie E, Feldt K, Raikkonen K, Phillips DI, Osmond C, Heinonen K, Pesonen AK, Andersson S, Barker DJ, Eriksson JG: Body size at birth predicts hypothalamic-pituitary-adrenal axis response to psychosocial stress at age 60 to 70 years. J Clin Endocrinol Metab 2007;92:4094-4100.

18 Pariente G, Sheiner E, Kessous R, Michael S, Shoham-Vardi I: Association between delivery of a small-for-gestational-age neonate and long-term maternal cardiovascular morbidity. Int J Gynaecol Obstet 2013;123:68-71.
19 Almasi O, Pariente G, Kessous R, Sergienko $\mathrm{R}$, Sheiner E: Association between delivery of small-for-gestational-age neonate and longterm maternal chronic kidney disease. J Matern Fetal Neonatal Med 2016;29:2861-2864.

20 Faienza MF, Brunetti G, Delvecchio M, Zito A, De Palma F, Cortese F, Nitti A, Massari E, Gesualdo M, Ricci G, Carbonara S, Giordano P, Cavallo L, Scicchitano P, Ciccone MM: Vascular function and myocardial performance indices in children born small for gestational age. Circ J 2016;80:958-963.

21 Sehgal A, Doctor T, Menahem S: Cardiac function and arterial biophysical properties in small for gestational age infants: postnatal manifestations of fetal programming. J Pediatr 2013;163:1296-1300.

22 Fujita K, Nagasaka M, Iwatani S, Koda T, Kurokawa D, Yamana K, Nishida K, TaniguchiIkeda M, Uchino E, Shirai C, Iijima K, Morioka I: Prevalence of small for gestational age (SGA) and short stature in children born SGA who qualify for growth hormone treatment at 3 years of age: population-based study. Pediatr Int 2016;58:372-376.

23 Villar J, Cheikh Ismail L, Victora CG, Ohuma EO, Bertino E, Altman DG, Lambert A, Papageorghiou AT, Carvalho M, Jaffer YA, Gravett MG, Purwar M, Frederick IO, Noble AJ, Pang R, Barros FC, Chumlea C, Bhutta ZA, Kennedy $\mathrm{SH}$, International Fetal and Newborn Growth Consortium for the 21st Century: International standards for newborn weight, length, and head circumference by gestational age and sex: the Newborn Cross-Sectional Study of the INTERGROWTH-21st Project. Lancet 2014;384:857-868.

24 Villar J, Giuliani F, Fenton TR, Ohuma EO, Ismail LC, Kennedy SH; INTERGROWTH21st Consortium: INTERGROWTH-21st very preterm size at birth reference charts. Lancet 2016;387:844-845. 